\title{
CONSTRUINDO A HISTÓRIA DOS BAIRROS: UM DIÁLOGO ENTRE MEMÓRIA E EDUCAÇÃO
}

\section{Resumo}

\author{
Tiago Pires \\ Universidade Estadual de Campinas - UNICAMP \\ tiago_pires@ymail.com \\ Carlos Alberto Pereira \\ Universidade Federal de Ouro Preto - UFOP \\ pereira@demin.ufop.br
}

Na contemporaneidade, a grande produção de informação faz com que os saberes e memórias do passado sejam substituídos pela constante inovação midiática, pautada em relações voláteis típicas da pós-modernidade. Durante grande parte da história do Brasil, a valorização de saberes, memórias e lugares somente ocorreu quando esses eram referentes às grandes personalidades, na maioria das vezes pertencentes à elite econômica. Em meio a esse contexto, desenvolvemos um projeto de pesquisa que objetivava resgatar as memórias, histórias e culinárias de bairros periféricos de Ouro Preto, Minas Gerais, Brasil. Visando valorizar esses saberes e sujeitos, iniciamos um processo de investigação, pautado na metodologia da história oral e do ensino de História por projetos, envolvendo os alunos da rede pública, bem como professores e historiadores. A pesquisa foi desenvolvida entre $2008 \mathrm{e}$ 2011, resultando na construção de um livro com fins didático-pedagógicos, intitulado "Saramenha: memórias, histórias e culinária".

Palavras-chave: Memória. Educação. Patrimônio. História.

\section{BUILDING THE HISTORY OF NEIGHBORHOODS: A DIALOGUE BETWEEN MEMORY AND EDUCATION}

\begin{abstract}
Nowadays, large-scale production of information makes the knowledge and memories of the past are replaced by constant media innovation, based on volatile relationships typical of postmodernity. Throughout much of the history of Brazil, the appreciation of knowledge, memories and places only occurred when these were related to the great personalities, mostly belonging to the economic elite. Within this context, we developed a research project that aimed to rescue the memories, stories and culinary of suburbs of Ouro Preto, Minas Gerais, Brazil. Aiming to enhance this knowledge and subjects, we initiated a process of research, guided by the methodology of oral history and history teaching by projects involving public school students as well as teachers and historians. The research was conducted between 2008 and 2011, resulting in the construction of a book with didactic-pedagogic purposes, entitled "Saramenha: memories, stories and cooking.
\end{abstract}

Keywords: Education. Patrimony. History. 


\section{INTRODUÇÃO}

$\mathrm{Na}$ contemporaneidade, a grande produção de informação faz com que os saberes e memórias do passado sejam substituídos pela constante inovação midiática, pautada em relações voláteis típicas da pós-modernidade. Durante grande parte da história do Brasil, a valorização de saberes, memórias e lugares somente ocorreu quando esses eram referentes às grandes personalidades, na maioria das vezes pertencentes à elite econômica. Os saberes comunitários presentes nos bairros, nas populações menos abastadas ou em outros grupos sociais são constantemente desconsiderados tanto pela academia quanto pelas escolas, que preferem utilizar o conhecimento legitimado pela racionalidade científica. São recentes no Brasil as políticas públicas voltadas para a valorização do patrimônio (material e imaterial) vinculado a grupos sociais menos favorecidos e excluídos. No bojo dessas discussões, desenvolvemos um projeto de pesquisa que visava resgatar a história e a memória de bairros periféricos de Ouro Preto/MG. Objetivava-se também, ao final desse processo, a construção de um livro com fins didáticos, voltado para as escolas da região, sobre as memórias e histórias do bairro. Dessa forma, reunimos ensino de história, memória, educação e valorização de sujeitos e saberes que por muito tempo permaneceram excluídos e desvalorizados em nossa sociedade.

Iniciamos nosso projeto em 2008 no bairro Saramenha de Cima, em Ouro Preto, e em 2011 demos continuidade a ele em outra localidade da cidade, no bairro Morro São Sebastião. No presente artigo, focaremos no projeto desenvolvido em Saramenha de Cima, que se encontra finalizado. Nosso trabalho se embasou na perspectiva do ensino de história por projetos, por meio da história local, na qual são valorizados e trabalhados saberes históricos a partir de realidades e memórias próximas das experiências dos estudantes. As atividades foram desenvolvidas junto com os alunos do Ensino Fundamental em horário extraclasse. Esse projeto consistiu na realização de entrevistas orais, na qual todos os envolvidos investigavam e colhiam depoimentos, fotos, receitas culinárias, dentre outros vestígios importantes para a construção das "histórias" do bairro. Junto a essa atividade, realizamos pesquisas em livros e arquivos históricos objetivando contrapor as diferentes versões acerca da história do bairro. Não pretendíamos montar uma história oficial, mas construir as 
diferentes "histórias" presentes no bairro a partir das memórias dos moradores, relacionandoas com aspectos gerais da história da região e do Brasil.

Ao final das pesquisas e entrevistas, sistematizamos todo o material recolhido a fim de montarmos um livreto contendo as memórias e as histórias identificadas. Intitulado Saramenha: memórias, histórias e culinária, o material foi finalizado no início de 2011 e então socializado para os moradores e participantes do projeto. Além de valorizarmos o conhecimento dos moradores do bairro e suas memórias, o projeto contribuiu para tornar o processo educativo mais interessante, fazendo com que os próprios estudantes se tornassem agentes históricos e construtores do saber escolar. Desse modo, o ensino por projetos tem como objetivo formar educandos autônomos no processo de investigação e aprendizagem, o que é feito de maneira participativa e construtiva. A partir dessa pesquisa, realizada entre 2008 e 2011, realizaremos no presente artigo uma discussão acerca das possibilidades de diálogo entre História, memória e educação, bem como identificaremos na construção das histórias dos bairros um potencial transformador das realidades sociais e individuais.

\section{MATERIAL E MÉTODOS}

Começaremos este tópico com a indagação inicial do trabalho de Lana Mara de Castro Siman: "pode a escrita da História de cidades, elaborada a partir do diálogo entre a memória e a História, oferecer a alunos e professores oportunidades de aprender a se perderem numa cidade?" (SIMAN, 2008, p.242). Adiantando o resultado da autora, podemos sim aprender e ao mesmo tempo valorizar os sujeitos que concordam em compartilhar suas histórias de vida, suas memórias. Em projetos relacionados a esse empreendimento da construção das histórias do bairro, não são somente os pesquisadores, alunos e professores que adquirem e produzem conhecimento, mas os próprios moradores que, ora são entrevistados, ora são entrevistadores. Falamos em histórias ou, como Siman (2008), em labirintos, visto que a história de uma comunidade não é fechada nem linear, e muito menos única. O que temos são vestígios de um tempo que passou e que continua presente a partir das memórias vivas, acessadas por meio de entrevistas e boas conversas.

No contexto em que vivemos, no qual as informações circulam e são produzidas numa velocidade imensurável, é possível manter algum interesse no passado? Tais aspectos, tão caros à nossa sociedade e à modernidade, constituem-se como obstáculo quando o assunto são as lembranças e as identidades remetidas ao pretérito. Se a relação com o passado mudou, pautando-se agora num relacionamento nostálgico, junto a um futuro incerto, o que nos resta 
seria somente o nosso presente? O hedonismo contemporâneo, tão discutido nos trabalhos sociológicos hodiernos que abordam a pós-modernidade, acaba por priorizar uma vivência demasiadamente marcada pela preocupação com o tempo presente. Nessa perspectiva, "como criar, para as novas gerações, nascidas num contexto de mudanças rápidas e numerosas, o sentido do passado e de orientação temporal para as suas vidas?" (SIMAN, 2008, p.244). Tais perspectivas refletem tanto no campo da vivência quanto no campo educacional, trazendo certos obstáculos nos usos e entendimentos do passado.

As políticas públicas têm investido na melhoria da educação, principalmente nos países que apresentam déficits na qualidade educacional e no acesso às escolas públicas. No Brasil, segundo pesquisas do IBGE, temos um aumento significativo na taxa líquida de escolarização no ensino fundamental entre os anos de 1980 a 2000, como apresenta a tabela abaixo. Contudo, é preciso questionar se a qualidade do ensino nas instituições públicas seguiu o mesmo rumo do aumento quantitativo do alunado brasileiro.

\begin{tabular}{|c|c|}
\hline \multicolumn{2}{|c|}{ Taxa líquida de escolarização por níveis de ensino } \\
\hline Período & Fundamental \\
\hline 1980 & 80.1 \\
\hline 1991 & 83.8 \\
\hline 1994 & 87.5 \\
\hline 1998 & 95.3 \\
\hline 1999 & 95.4 \\
\hline 2000 & 94.3 \\
\hline Quadro 1 - Taxa líquida de escolarização no Brasil. Fonte: IBGE \\
\hline \multicolumn{2}{|c|}{ Fonte: Elaborado pelos autores. } \\
\hline
\end{tabular}

O desinteresse e o fracasso escolar são um dos problemas mais recorrentes em sala de aula, além de serem muito discutidos entre educadores e pesquisadores. As causas são variadas e complexas, assim como as suas soluções. Segundo Bernard Charlot (2000, p.14),

\footnotetext{
A questão do fracasso escolar remete para muitos debates: sobre o aprendizado, obviamente, mas também sobre a eficácia dos docentes, sobre o serviço público, sobre as igualdades das "chances", sobre os recursos que o país deve investir em seu sistema educativo, sobre a 'crise', sobre os modos de vida e o trabalho na sociedade de amanhã, sobre as formas de cidadania, etc.
}

Compartilhamos com as ideias de Charlot, o qual acredita que o desinteresse pelos conteúdos escolares está em grande parte relacionado à falta de identidade entre o que é discutido (ou reproduzido) em sala e a realidade e subjetividade dos estudantes. Em certa medida, a escola não acompanhou as mudanças ocorridas na sociedade, desprezando, muitas 
vezes, os conhecimentos produzidos no meio social e cultural dos discentes. Por isso, nos preocupamos em realizar atividades que possam mobilizar não só alunos, mas professores e moradores dos bairros em que realizamos nosso trabalho. O saber é uma forma de se relacionar com o mundo (CHARLOT, 2000, p.60) e, dessa forma, acreditamos que a construção da história de um bairro junto aos seus moradores mostra-se como um caminho plausível para a valorização desses sujeitos e para a construção de uma identidade que muitas vezes é desvalorizada ou encontra-se ausente dentro de algumas comunidades. Mas não se cria uma relação com o mundo sem veicular um saber em que os sujeitos se identifiquem, visto que

[...] qualquer relação com o saber comporta também uma dimensão de identidade: aprender faz sentido por referência à história do sujeito, às suas expectativas, às suas referências, à sua concepção de vida, às suas relações com os outros, à imagem que tem de si e à que quer dar de si aos outros (CHARLOT, 2000, p.72).

As maneiras de ser e estar no mundo se modificaram significativamente com o advento da modernidade, criando um novo tipo de sujeito, cada vez mais autônomo e desvinculado de qualquer instituição única e centralizadora no fornecimento de sentido à existência humana (BERGER; LUCKMANN, 1996). História e memória formam um conjunto muito rico na construção de identidades locais, regionais e nacionais. O ensino de história tem sido muito utilizado como instrumento na construção de identidades entre alunos, professores e suas localidades de nascença ou residência, como mostra o artigo de Siman (2008) e outros trabalhos que discutem o ensino da história local, como Monteiro, Gasparello, Magalhães, (2007) e Buarque (2010). Contudo, segundo Allieu (apud MONTEIRO, 2005), a dimensão da memória e da identidade no ensino de história encontra-se em crise na contemporaneidade:

\begin{abstract}
A memória: em nosso universo ocidental multicultural, sobre quais raízes construir, qual memória ensinar hoje em dia? Até muito recentemente, operávamos a partir de uma escolha realizada pelo Estado que definia que passado seria necessário conhecer e lembrar. Nos dias atuais, confronta-nos o desafio de contemplar a multiplicidade do mundo e sua indeterminação para auxiliar nossos alunos a construir sua memória e sua identidade a partir de uma história que considere as rupturas, conflitos, crises públicas e privadas, em suas infinitas diferenças (ALLIEU apud MONTEIRO, 2005, p.446).
\end{abstract}

De acordo com Le Goff (1992), tornar-se senhor “da memória e do esquecimento é uma das grandes preocupações das classes, dos grupos, dos indivíduos que dominaram e dominam as sociedades históricas" (LE GOFF, 1992, p.426). Muito recentemente, as políticas públicas brasileiras têm fornecido a devida atenção aos "lugares de memória" localizados em 
regiões periféricas e pertencentes a comunidades minoritárias ou excluídas da sociedade. As políticas de preservação patrimonial voltam-se, geralmente, para a preservação dos monumentos consagrados às elites econômicas, aos sujeitos "notáveis", deixando de lado outros objetos e saberes. Por que não conservar a história de um bairro periférico? Somente os centros históricos possuem valor patrimonial? Todo bairro e toda comunidade, grande ou pequena, rica ou pobre, nova ou antiga, possui a sua história, e é na história local que os moradores encontram a sua identificação inicial, o seu pertencimento, a sua identidade coletiva e individual. Levantar a história dos bairros é dar voz a outros "lugares de memória", a outros sujeitos, a outros saberes. A memória ocupa um espaço privilegiado no fornecimento de sentido à existência humana e na democratização e valorização de diferentes saberes, visto que ela "é um elemento essencial do que se costuma chamar identidade, individual ou coletiva, cuja busca é uma das atividades fundamentais dos indivíduos e das sociedades de hoje, na febre e na angústia" (LE GOFF, 1992, p.476).

A memória constitui-se como uma fonte essencial para a construção da história e da identidade de indivíduos e grupos sociais. Outro ponto positivo dessa relação memóriahistória é a valorização de sujeitos que, muitas vezes, não possuem um espaço social para expressar a sua cultura, identidade e a sua maneira de perceber e estar no mundo. E um dos caminhos para que essas "comunidades esquecidas" sejam reconhecidas, assim como reconheçam e valorizem a si próprias, é a partir da relação entre memória, história e educação na construção das histórias locais, do bairro, da família e de pessoas. Afinal, como realizar tal desafio?

Em 2002, com o intento de resgatar a arte e o ofício da cantaria na região de Ouro Preto (Minas Gerais, Brasil) e adjacências, assim como a sua preservação, surgiu o Projeto Cantaria, hoje um Programa de Extensão que engloba uma série de outras atividades. Em consonância com o Programa Cantaria, iniciamos em 2008 o projeto Oficina de ciência e cidadania, o qual visava implantar nos bairros afastados da região central de Ouro Preto bibliotecas comunitárias que servissem como espaço cultural e de sociabilidade, além de ser um meio de suprir as necessidades educacionais referentes à leitura e aos outros saberes escolares. Em diálogo com as propostas da Oficina de ciência e cidadania, desenvolvemos um projeto de extensão que almejava resgatar a história e a memória de bairros periféricos de Ouro Preto/MG. Objetiva-se também, ao final desse processo, a construção de um livro com fins didático-pedagógicos, voltado para as escolas da região, sobre as memórias e histórias do bairro. Dessa forma, reunimos ensino de história, memória, educação e valorização de sujeitos 
e saberes que por muito tempo permaneceram excluídos e desvalorizados em nossa sociedade. Esse projeto é uma tentativa de responder aos problemas e às indagações postas acima, referentes à atual relação entre memória, história e educação. No presente texto nos ateremos à discussão do trabalho, já finalizado, realizado no bairro Saramenha, em Ouro Preto, Minas Gerais.

Estruturamos, construímos e desenvolvemos nosso projeto nos embasando nos referencias teóricos delineados por Bernard Charlot (2000) sobre a questão da mobilização dos indivíduos e da relação de identidade com o saber, nas definições de Le Goff (1992) sobre os usos e diálogos entre memória e história e na importância da construção das histórias dos bairros discutida por Siman (2008).

Ao longo do projeto Oficina de ciência e cidadania, instalado inicialmente no bairro Saramenha de Cima, percebemos a riqueza dos saberes, dos patrimônios materiais e imateriais (pessoais e coletivos) e, ao mesmo tempo, a desvalorização e a não percepção por parte dos moradores de tão valorosa cultura. A história do bairro de Saramenha, desde os tempos mais remotos até o contexto hodierno, está repleta de memórias, histórias e práticas culturais que passam despercebidas pelas políticas públicas da região. Tal fato nos instigou a iniciarmos um projeto que visasse resgatar e valorizar tais aspectos e, ao mesmo tempo, fazer com que os moradores percebessem sua importância na constituição do patrimônio cultural e identitário de Ouro Preto. Desde então, lançamo-nos nessa árdua tarefa, que perdurou até o início de 2011.

Montamos uma equipe destinada a realizar a pesquisa, formada pelos discentes do curso de História e Nutrição, sob a coordenação de professores e historiadores. Contudo, essas pessoas não foram as únicas participantes do projeto. Os moradores do bairro de Saramenha, bem como os alunos e professores das escolas adjacentes, também se tornaram construtores da história do bairro, ora como investigadores, ora como entrevistados. A história local não foi redigida apenas num viés interpretativo acadêmico, mas contou com os diferentes olhares advindos dos depoentes, daqueles que forneciam suas memórias. Nenhum saber (comunitário ou acadêmico) se sobrepôs ou se mostrou mais validado, nem mais importante. O diálogo entre diferentes leituras de mundo possibilitou a construção de labirintos dentro de várias histórias que foram se formando. Em certos momentos, como também aponta Siman (2008), nos perdíamos nos labirintos do bairro em meio a muitos depoimentos e memórias, orais e escritos, criando diferentes versões acerca da mesma temática. Quando se trabalha com história do bairro a partir da memória dos moradores, não se constrói uma, mas várias 
histórias, exatamente porque cada morador é um sujeito e, dessa forma, possui uma leitura de mundo e uma vivência específicas (CHARLOT, 2000, p.72). É claro que muitos dos caminhos desse labirinto se encontravam, o que possibilitou a continuidade do projeto, assim como intensificou o nosso interesse pelo assunto. Ao invés de um tempo progressivo, representado por meio de uma reta,

[...] temos um tempo labiríntico, cheio de sinuosidades e que, para compreendê-lo, é preciso aprender a decifrar sinais, indícios e as mais aparentes insignificâncias: desde o rosto daqueles que circulam as ruas no presente, aos gestos, esquecimentos, pausas, olhares, um pedaço de papel retirado da gaveta pelo narrador, às ruínas presentes no espaço da cidade, aos sinais escondidos pelas camadas das intervenções humanas. (SIMAN, 2008, p.262).

Depois de selecionada a equipe, partimos para o levantamento histórico, a partir de entrevistas concedidas pelos moradores do bairro de Saramenha e da investigação em arquivos históricos e livros de referência. Não encontramos material suficiente nas fontes manuscritas e impressas. Para tanto, foi preciso que o enfoque de nosso projeto recaísse sobre os depoimentos orais recolhidos em entrevistas realizadas nas próprias casas dos entrevistados. Mais do que entrevistas, nossos encontros com a comunidade se tornaram boas conversas, harmonia essa necessária para todo trabalho de história oral. Para realizarmos as entrevistas nos embasamos na metodologia formulada por autores especialistas no assunto, como Ecléa Bosi (1994), Verena Alberti (2007) e Marieta de Moraes Ferreira e Janaína Amado (1998). Os assuntos que serviram de orientação para a coleta de depoimentos foram: a história do bairro (antiga e atual), a história do entrevistado e de sua família, a culinária local, as manifestações culturais, dentre outros temas afins. Em paralelo ao levantamento da história de Saramenha, também muito nos interessou a culinária local, que assumiu em nosso projeto espaço significativo. Além das entrevistas, marcávamos na casa dos moradores um dia específico para que eles cozinhassem uma receita típica do bairro ou de suas famílias, investigando os usos e a história da receita.

Finalizada a fase de coleta, iniciamos o processo de transcrição das entrevistas orais. Posteriormente, começamos a sistematizar todo o material recolhido (fotos, entrevistas, textos) e selecionar o que seria inserido no livro que objetivávamos montar. O livro começou a ser redigido em meados de 2010, finalizado no princípio de 2011. Acreditamos que o material impresso adquire um valor simbólico muito propício à valorização da comunidade. Os moradores do bairro, quando avisados que as pesquisas resultariam em um livro sobre o bairro, ficaram mais animados e dispostos a conceder os depoimentos. Não é qualquer bairro que possui um livro sobre sua história, construída em grande parte pelo material e pela 
atuação dos moradores. Ora, se nosso objetivo inicial e derradeiro era a valorização e o resgate dessas memórias e histórias, nada mais coerente que publicar, em material impresso, o conteúdo recolhido. Até agora falamos sobre a relação entre memória e história, mas em qual parte encontra-se a dimensão educativa de nosso projeto?

A dimensão educativa de nosso projeto está presente desde sua montagem e envolve todos os seus participantes, professores, pesquisadores e moradores do bairro. Em relação aos primeiros, notamos a valiosa formação cidadã e consciente dos discentes na medida em que se relacionavam com a comunidade. Os conhecimentos teóricos adquiridos na academia adquiriram novas roupagens ao dialogarem com os saberes, não menos importantes, advindos da comunidade. A dimensão prática e a responsabilidade social são dimensões importantíssimas na universidade, sobretudo nos projetos extencionistas. Tais ações, de forma alguma, redundaram em caridade ou assistencialismo social. Nossa proposta não foi levar conhecimento científico aos moradores supostamente "sem cultura", mas dialogar diferentes visões de mundo, distintos saberes que se completam, cada um na sua importância e singularidade.

Inicialmente, objetivávamos construir um livro sobre a história do bairro, num viés monográfico. Mas, percebendo a carência dos materiais didáticos referentes à história de Ouro Preto e mesmo do bairro, sentimos a necessidade e compreendemos ser mais valioso que o material final fosse de cunho didático-pedagógico, voltado para o ensino de história nas escolas do bairro e da região. Para a construção do livro, nos embasamos em autores que discutem a importância da história local no ensino de história e na construção de identidades, sobretudo a partir da formulação de projetos. Pautamo-nos em trabalhos desenvolvidos por Siman (2005, 2008), Monteiro (2005, 2007), Buarque (2010), Pereira (2008), dentre outros autores que discutem a temática. O levantamento da história do bairro também contou com a participação de alunos e professores das escolas do entorno de Saramenha, constituindo-se, dessa forma, como um projeto pedagógico, tanto em seu desenvolvimento quanto em seu produto final.

Quando desenvolvemos um trabalho que envolve o ensino de história a partir da história local, não podemos pensar a construção desse saber desvinculado de um contexto maior relacionado à região, Estado ou país. Em nosso projeto, quando abordamos a culinária do bairro, por exemplo, ligamos o conteúdo levantado com a história da alimentação e sociedade mineira, mais especificamente na região de Ouro Preto e Mariana. Outro ponto abordado foi a industrialização do bairro Saramenha com a vinda da fábrica Elquisa e de 
imigrantes estrangeiros, temática esta que está vinculada ao processo de imigração e industrialização do Brasil nas primeiras décadas do século XX.

\section{RESULTADOS E ANÁLISE}

O livro, intitulado Saramenha: memórias, histórias e culinária, encontra-se finalizado, aguardando publicação. Ao saberem do livreto, os moradores do bairro ficaram muito interessados em apreciar o trabalho final. O livro já foi apresentado a alguns moradores, que receberam o material com muita satisfação, agradecidos e engrandecidos por tal empreendimento. Tais ocorrências mostram indícios do quão importante esse trabalho se tornará para os moradores do bairro de Saramenha e para as escolas do entorno, assim como para os pesquisadores e professores envolvidos.

O livro, apesar de se constituir como material de cunho didático-pedagógico, também é destinado aos moradores do bairro, que em muito contribuíram para a sua construção. Ao longo do material encontram-se espaços interativos, com algumas atividades lúdicas, dispostos de forma a fazer com que os leitores construam e participem ativamente da elaboração da história do bairro e da sua própria vida. O livro está dividido em diversos setores, como: minha página, introdução, culinária mineira, receitas, minha receita, biblioteca comunitária, história do bairro, entrevistas, palavra-cruzada, fotos, agradecimentos e referências. Além de remeter a conteúdos contemporâneos, o livro de Saramenha também aborda a história do bairro desde tempos remotos, num diálogo entre passado e presente.

O livro foi construído sob uma perspectiva teórica que considera a história do bairro não como uma narrativa linear, pronta e fechada. Não é por acaso que nos apropriamos do termo "labirintos do bairro", utilizado por Siman (2008), para definir as várias memórias, histórias e culinária encontradas em meio a depoimentos orais e escritos. A vivência humana não é exata, não é única, mas é tensional e contraditória. Tendo isso em vista, seria impossível construirmos uma história oficial do bairro, pois a história de Saramenha ainda não acabou e, dessa forma, não pode ser finalizada e reduzida a um simples livro. Nosso produto final não objetivou incorporar todos os depoimentos recolhidos, nem todas as memórias que nos foram dispostas. Aliás, isso seria impossível. Nosso livro foi um recorte, uma escolha que esperamos ser útil para valorizar os moradores e seus saberes e patrimônios, ajudar a construir identidades coletivas e individuais, assim como fornecer ferramentas suficientes para compreender a História a partir de uma realidade mais próxima e agradável aos moradores, alunos e professores da comunidade e do entorno de Saramenha. 


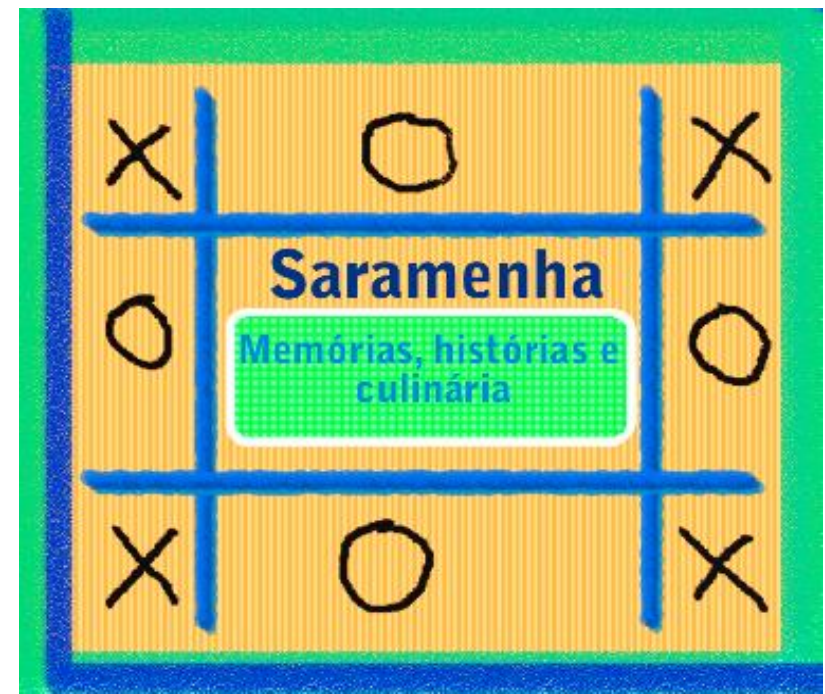

Figura 1 - Capa do Livro Fonte: Elaborado pelos autores.

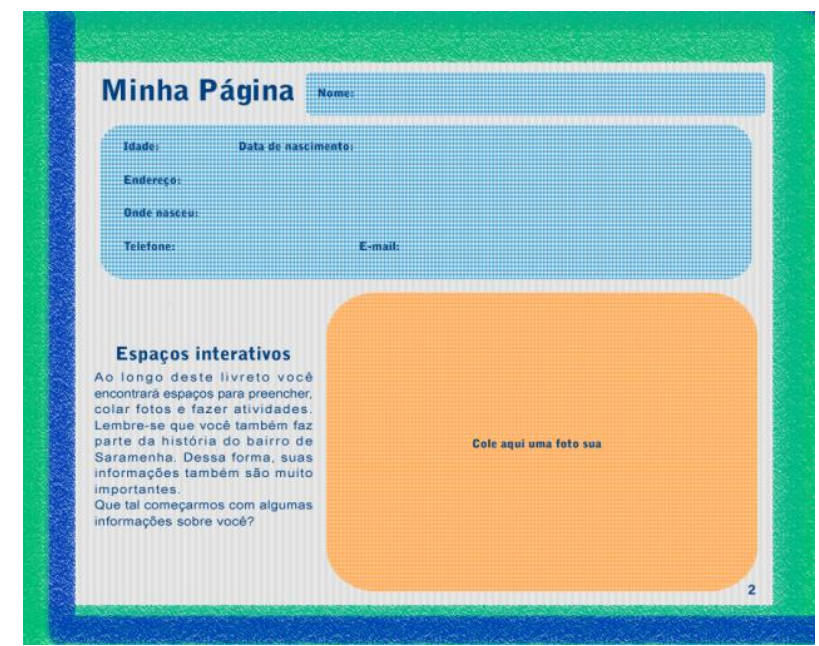

Figura 2 - Página interativa Fonte: Elaborado pelos autores.

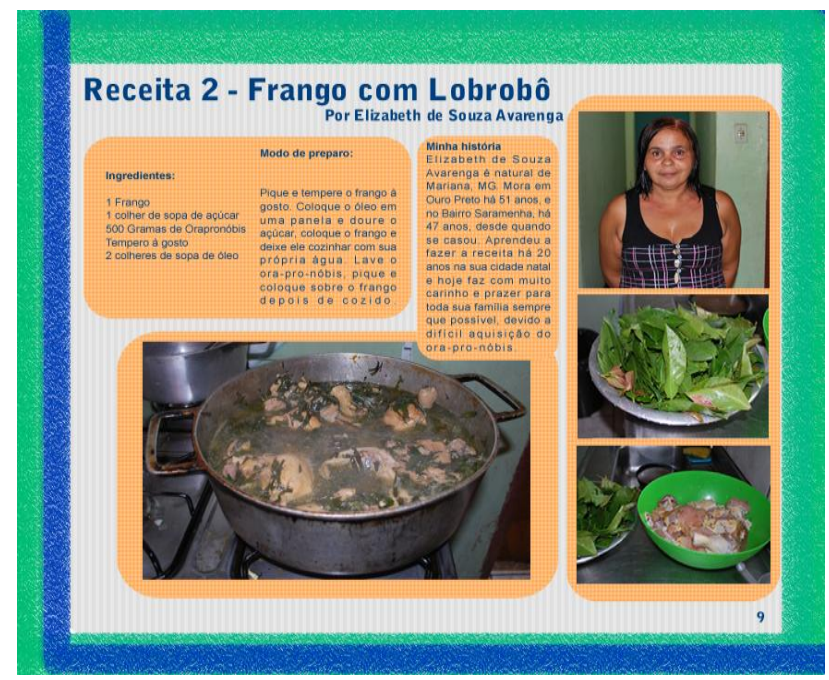

Figura 3 - Página de receita culinária Fonte: Elaborado pelos autores. 


\section{CONSIDERAÇÕES FINAIS}

É sempre complicado delimitarmos os resultados alcançados ou percebermos se eles efetivamente penetraram no âmago de cada sujeito envolvido. $O$ alcance das ações extencionistas sempre ultrapassa nossos olhares, pois cada um vai receber e interpretar o levantamento da história do bairro de maneira específica. Nosso projeto não foi desenvolvido almejando construir uma história oficial que deveria ser levada para a comunidade de Saramenha, a fim de servir como material identitário para aquelas pessoas. Nós objetivamos, desde o início, envolver os moradores na construção dessas histórias, englobando diferentes olhares sobre o passado e presente. Tais caminhos, apesar de difíceis de serem reunidos numa narrativa, possibilitaram uma ação que está para além da simples escrita de um livro. Essas histórias, memórias e culinária levantadas, mesmo que parcialmente resgatadas, ainda permanecem presentes, se modificando a cada dia e, dessa forma, assumindo diferentes facetas. A história de Saramenha não acabou e, certamente, nunca acabará. Um livro não conseguirá esgotar tamanha multiplicidade e riqueza cultural. Esperamos que a finalização de nosso projeto e seu produto final abarque a função que a memória pode exercer, como aponta o historiador Jacques Le Goff: "A memória, onde cresce a história, que por sua vez a alimenta, procura salvar o passado para servir o presente e o futuro. Devemos trabalhar de forma a que a memória coletiva sirva para a libertação e não para a servidão dos homens" (LE GOFF, 1992, p.477).

\section{REFERÊNCIAS}

ALBERTI, Verena. Manual de História Oral. 3. ed.. Rio de Janeiro: Editora FGV, 2007.

AMADO, Janaína; FERREIRA, Marieta de Moraes. Usos \& abusos da história oral. Rio de Janeiro: Editora FGV, 1998.

BERGER, Peter L.; LUCKMANN, Thomas. Modernidad, pluralismo y crisis de sentido ¿qué necesidades humanas básicas de orientación deben ser satisfechas? Estudios Públicos, n. 63, 1996.

BITTENCOURT, Circe Maria Fernandes. Ensino de História: fundamentos e métodos. $1^{\text {a }}$.Ed.São Paulo: Cortez, 2005. 
BRASIL. Ministério da Educação. Secretaria de Educação Fundamental. Parâmetros Curriculares Nacionais para o Ensino Fundamental. Brasília: MEC, SEF, 1998.

BUARQUE, Virgínia A. de Castro (org). Curtas em Mariana e Ouro Preto: identidades através do ensino de História. Ouro Preto: Editora UFOP, 2010.

CHARLOT, Bernard. Da relação com o saber: elementos para uma teoria. Porto Alegre: ARTMED, 2000.

FONSECA, Thais Nívia de Lima. História e Ensino de História. $2^{\text {a }}$ ed. Belo Horizonte: Autêntica, 2003.

LAVILLE, Christian. A guerra das narrativas: debates e ilusões em torno do ensino de história. Revista Brasileira de História, São Paulo. v.19, n. 38, p. 125-138, 1999. Disponível http://www.scielo.br/pdf/rbh/v19n38/0999. Acesso em 11 mar. 2011.

LE GOFF, Jacques. História e memória. 2a ed. Campinas: Editora da Unicamp, 1992.

KARNAL, Leandro (org.). História na Sala de Aula: conceitos, práticas e propostas. São Paulo: Contexto, 2003.

MONTEIRO, Ana Maria F. C.; GASPARELLO, Arlette Medeiros; MAGALHÃES, Marcelo de Souza (org.). Ensino de história: sujeitos, saberes e práticas. Rio de Janeiro: Mauad X: FAPERJ, 2007.

MONTEIRO, Ana Maria F. C. Ensino de História e história cultural: diálogos possíveis. In: SOIHET, Rachel; BICALHO, Maria Fernanda B.; GOUVÊA, Maria de Fátima S. (org). Culturas políticas: ensaios de história cultural, história política e ensino de história. Rio de Janeio: Mauad, 2005.

NORA, Pierre. Entre a memória e a história: a problemática dos lugares. Projeto historia. São Paulo, n. 10, p. 7-28, dez. 1993.

PEREIRA, Junia Sales. Aprendizagem histórica como prática social: lições poéticas e éticas em "A danação do objeto: o museu no ensino de história". Educação em Revista, Belo Horizonte, n. 47, jun. 2008.

RICOEUR, Paul. A memória, a história, o esquecimento. Campinas: Editora da Unicamp, 2007. 
SIMAN, Lana Mara de Castro. Representações e memórias sociais compartilhadas: desafios para os processos de ensino e aprendizagem da história. Cad. Cedes, Campinas, v. 25, n. 67, p. 348-364, set./dez. 2005.

Memórias sobre a história de uma cidade: a história como labirinto. Educação em Revista, Belo Horizonte, n. 47 jun. 2008.

SIMAN, Lana Mara de Castro; MIRANDA, Sonia Regina. Apresentação: Dossiê Práticas de memória e ensino de história. Educação em Revista, Belo Horizonte, n. 47, jun. 2008. 